\title{
Penerapan budaya 7K untuk siswa sekolah dasar
}

\author{
Any Budiarti *, S. Sriawan \\ Universitas Negeri Yogyakarta. Jl. Colombo No. 1 Yogyakarta, 55281, Indonesia \\ * Corresponding Author. Email: Any.Budiarti@gmail.com
}

\begin{abstract}
Abstrak
Penelitian ini bertujuan untuk mengetahui pelaksanaan penerapan budaya 7K (Keamanan, Kenyamanan, Kebersihan, Ketertiban, Keindahan, Kekeluargaan, dan Kerindangan) yang dilakukan oleh siswa kelas IV, V, VI di SD Negeri 7 Kebumen, Kecamatan Kebumen. Desain penelitian ini adalah penelitian deskriptif dengan metode survei. Subjek dari penelitian ini adalah seluruh siswa kelas IV, V, VI di SD Negeri 7 Kebumen, Kecamatan Kebumen. Jumlah siswa keseluruhan yang diteliti sebanyak 100 siswa. Teknik pengambilan data menggunakan angket. Validitas kontsruk instrumen penelitian dengan expert judgement dan validitas instrumen angket dilakukan dengan analisis butir. Uji reliabilitas menggunakan rumus Alpha Cronbach. Teknik analisis data yang digunakan dalam penelitian ini adalah analisis data statistik deskriptif. Hasil penelitian disimpulkan bahwa penerapan budaya $7 \mathrm{~K}$ pada faktor yang dikategorikan sangat baik ada 2 faktor yaitu ketertiban dan kekeluargaan dengan presentase keseluruhan sebesar $28,6 \%$, pada kategori baik ada 4 faktor yaitu keamanan, kenyamanan, kebersihan dan keindahan dengan presentase keseluruhan sebesar $57,1 \%$, pada kategori cukup ada 1 faktor yaitu kerindangan dengan presentase keseluruhan sebesar $14,3 \%$, dan kategori tidak baik dengan presentase $0 \%$. Sehingga hasil penelitian penerapan budaya $7 \mathrm{~K}$ di SD Negeri 7 Kebumen, Kecamatan Kebumen adalah baik.
\end{abstract}

Kata Kunci: Budaya, 7K, Siswa SD

\section{Implementing the 7K culture among the elementary school students}

\begin{abstract}
The study aims at identifying the implementation of the 7K Culture (Keamanan or Security, Kenyamanan or Comfort, Kebersihan or Cleanliness, Ketertiban Order, Keindahan or Beauty, Kekeluargaan or Fraternity and Kerindangan or Shadiness) that the Grade IV, V and VI students of Negeri 7 Elementary School Kebumen internalize. The design of the study itself is a descriptive research using survey. When the study was conducted, 100 students from Grade IV, V and VI of the elementary school had been involved. Then, the data were gathered by means of questionnaire. The construct validity of the research instrument was measured by using the expert judgment, while the construct validity of the questionnaire was measured by using the item analysis. Next, the reliability of the instrument was measured by using the Alpha Cronbach formula. With regards to the nature of the study, the data analysis technique that had been adopted was the descriptive statistical data analysis. The results of the study show that: (1) the implementation of the 7K Culture with the "Very Good" category is found in two factors namely Order and Fraternity (overall percentage 28.60\%); (2) the implementation of the 7K Culture with the "Good" category is found in four factors namely Security, Comfort, Cleanliness and Beauty (overall percentage 57.10\%); (3) the implementation of the 7K Culture with the "Moderate" category is found in one factor namely Shadiness (overall percentage 14.30\%); and (4) the implementation of the 7K Culture with "Poor" category is not found in any factor (overall percentage $0.00 \%$ ). In brief, it might be concluded that the implementation of the 7K Culture in the Negeri 7 Elementary School Kebumen belongs to the "Good" category.
\end{abstract}

Keywords: Culture, 7K, Elementary School students 


\section{PENDAHULUAN}

Pendidikan bermula dari keluarga, lingkungan sekolah dan lingkungan masyarakat. Pendidikan dari keluarga dan dari masyarakat di dapatkan setiap hari pada saat melakukan aktifitas, sedangkan pendidikan formal di dapatkan dari sekolah. Pendidikan yang diterima di sekolah merupakan bekal yang sangat berharga guna menghadapi tantangan zaman yang semakin lama mengalami perkembangan.

Menurut Departemen Pendidikan Nasional (2001) Sekolah sebagai suatu lembaga pendidikan merupakan small community, suatu masyarakat dalam skala kecil, sehingga gagasan untuk mewujudkan masyarakat madani perlu diwujudkan dalam tata kehidupan sekolah, yang salah satunya melalui pendidikan budi pekerti yang nyata di lakukan (inaction), bukan yang semata-mata yang dipersepsi. Sedangkan menurut Djohar (1999) sekolah menjadi tempat mensosialisasikan nilai-nilai budaya, tidak hanya terbatas pada nilainilai keilmuan tetapi semua nilai-nilai kehidupan yang memungkinkan mampu mewujudkan manusia berbudaya. Sebagai pusat pengembangan budaya, sekolah selain mensosialisasikan nilai-nilai budaya yang telah hidup, juga diharapkan mampu melahirkan, menumbuhkembangkan nilai-nilai budaya baru yang menuntut untuk disosialisasikan melalui pendidikan.

Budaya di sekolah banyak sekali yang diterapkan seperti budaya membuang sampah pada tempatnya, menerapkan 7S (Senyum, Salam, Sapa, Sopan, Santun, Sabar, Syukur), di sekolah dasar selain menerapkan budaya tersebut juga melakukan baris di depan kelas sebelum masuk ke kelas. Dari sekian banyak budaya yang diterapkan, sekolah juga menerapkan budaya 7K (Kemanan, Kenyamanan, Kebersihan, Ketertiban, Keindahan, Kekeluargaan, dan Kerindangan).

Berdasarkan observasi yang telah dilakukan peneliti di SD Negeri 7 Kebumen kecamatan Kebumen dengan melakukan wawancara dengan kepala sekolah dan para guru sudah menerapkan budaya 7K (keamanan, kenyamanan, kebersihan, ketertiban, keindahan, kekeluargaan, kerindangan). Dalam penerapan budaya 7K ini setiap harinya sudah dilakukan oleh siswa namun belum secara maksimal, siswa sudah melaksanakan tetapi belum mengerti bagaimana penerapan yang sesuai dari masing-masing prinsip yang terkandung di di dalamnya seperti keamanan, kenyamanan, kebersihan, ketertiban, keindahan, kekeluargaan, kerindangan tersebut.

Harapan sekolah tentang pelaksanaan ditinjau dari aspek-aspek yang terkait yaitu dapat meningkatkan keamanan warga sekolah yang semakin membaik (keamanan diri sendiri dan keamanan sekolah), kesadaran siswa tentang kebersihan diri sendiri dan lingkungan sekolah, disiplin yang dilakukan warga sekolah agar tidak melanggar peraturan yang telah di buat sekolah, warga sekolah dapat menciptakan keindahan yang semakin tertata dengan baik, hubungan antar warga sekolah yang baik, menciptakan kerindangan sekolah yang semakin baik. Dalam penerapan budaya 7K ini setiap harinya sudah dilakukan oleh siswa namun belum secara maksimal, siswa sudah melaksanakan tetapi belum mengerti bagaimana penerapan yang sesuai dari masing-masing prinsip yang terkandung di dalamnya seperti keamanan, kenyamanan, kebersihan, ketertiban, keindahan, kekeluargaan, kerindangan tersebut.

Sekolah tentu memiliki harapan bahwa penerapan tentang pelaksanaan 7K ditinjau dari aspek-aspek yang terkait yaitu dapat meningkatkan tata kehidupan seperti apa yang dimaksud dalam butir-butir tersebut, sebagaimana para guru sudah memberi contoh dalam kehidupan iklim di sekolah. Namun demikian tentu tidak serta merta para siswa bisa memahami dan dapat menerapkannya semua ada proses perkembangan, oleh karena itu bagaimana keadaan yang sesungguhnya ada pada Sekolah Dasar Kebumen 7 Kecamatan Kebumen.

Mengenai pengertian budaya, pada dasarnya masing-masing tokoh memberikan batasan-batasan yang berbeda tetapi pada prinsipnya memiliki konsep yang sama, karena unsur-unsur yang terdapat dalam kebudayaan memiliki kecenderugan yang sama. Menurut Ki Hajar Dewantara, kebudayaan berarti buah budi manusia yang merupakan hasil perjuangan manusia terhadap dua pengaruh yang kuat yaitu alam dan zaman atau kodrat 
dan masyarakat, (Tilaar, 1999). Selanjut disebutkan bahwa budaya sekolah adalah pola nilai-nilai, norma-norma, sikap, ritual, mitos, dan kebiasaan-kebiasaan yang terbentuk dalam perjalanan panjang sekolah, dimana budaya sekolah tersebut dipegang bersama oleh kepala sekolah, guru, staf, maupun siswa, sebagai dasar mereka dalam memahami dan memecahkan berbagai persoalan yang muncul di sekolah. Sekolah sebagai pusat pengembangan budaya, maka selain mensosialisasikan nilai-nilai budaya yang telah hidup, juga diharapkan mampu melahirkan, menumbuhkan dan mengembangkan nilai-nilai budaya baru yang menuntut untuk disosialisasikan melalui pendidikan (Djohar, 1999). Selanjutnya disebutkan bahwa pendidikan adalah proses budaya, yakni menyiapkan masyarakat untuk mampu memasuki kehidupan pada zamannya, para peserta didik disosialisasikan dengan nilai-nilai budaya yang akan berlaku dalam tatanan kehidupan pada zamannya itu, oleh karena itu pendidikan berlaku bagi semua orang dan terjadi disepanjang masa. Jadi dapat disimpulkan bahwa budaya sekolah merupakan kepercayaan, nilai, norma, sikap, kebiasaan dan sejarah sekolah, serta cara pandang dan memecahkan persoalan-persoalan yang ada di sekolah, juga diharapkan mampu melahirkan, menumbuhkan dan mengembangkan nilai-nilai budaya baru yang menuntut untuk disosialisasikan melalui pendidikan.

Unsur yang mempunyai fungsi yang baik dan dapat dikembangkan sebagai budaya di sekolah salah satunya yaitu 7K (Keamanan, kenyamanan, kebersihan, ketertiban, keindahan, kekeluargaan, dan kerindangan).

Menurut peraturan menteri pendidikan nasional nomor 39 tahun 2008 tentang pembinaan budi pekerti luhur atau akhlak mulia, antara lain (a) Melaksanakan tata tertib atau kultur sekolah; (b) Melaksanakan gotong royong dan kerja bakti (bakti sosial); (c) Melaksanakan norma-norma yang berlaku dan tatakrama pergaulan; (d) Menumbuhkembangkan sikap hormat dan menghargai warga sekolah; (e) Melaksanakan kegiatan 7K (keamanan, kebersihan, ketertiban, keindahan, kekeluargaan, kedamaian dan kerindangan).

Menurut Departemen Pendidikan Nasional, (2001) tentang tatakrama dan tatatertib kehidupan sosial sekolah bagi kepala sekolah, guru dan pegawai sekolah, yaitu memberikan gagasan baru dalam melaksanakan dan meningkatkan 7K (keamanan, kenyamanan, keberhasilan, ketertiban, keindahan, kekeluargaan, dan kerindangan) dalam lingkungan sekolah.

Menurut Oscar Gare Fufindo (2013) bahwa hasil Pembinaan Kepribadian dan budi pekerti luhur poin (a) tentang melaksanakan tata tertib dan kultur sekolah, bentuk pembinaan yang dilakukan oleh sekolah diantaranya melalui : melaksanakan $7 \mathrm{~K}$, bentuk pembinaan yang diakukan oleh sekolah diantaranya melalui mengajak siswa untuk selalu menjaga keindahan sekolah, memberikan sanksi bagi siswa yang melanggar ketertiban sekolah, memberikan keteladanan kepada siswa mengenai kebersihan diri dan kerapian dalam berpakaian. Selanjutnya sekolah memberikan pembinaan kepada siswa dengan meaksanakan razia kelas, razia kebersihan dan kerapian siswa dalam disiplin berpakaian, mengajak siswa menjaga hubungan kekeluargaan dan perdamian di sekolah dan di lingkungan masyarakat, memberikan keteladanan kepada siswa untuk selalu menjaga keamanan sekolah, serta meningkatkan kebersihan sekolah dengan melaksanakan lomba kebersihan kelas.

Perubahan budaya sekolah pada pokoknya ditentukan oleh atmosfer budaya yang dikembangkan oleh kepala sekolah bersama dengan guru-guru, gaya kepemimpina sekolah, nilai-nilai masyarakat sekolah, ukuran organisasi, tantangan, dan perubahan akan mempengaruhi budaya organisasi sekolah itu sendiri (Syafaruddin, 2002). Perubahan budaya sekolah misalnya dari sub-sub tentang $7 \mathrm{~K}$ yang dikemukakan Menurut peraturan menteri pendidikan nasional nomor 39 tahun 2008, tidak semua sekolah menggunakan semua sub tersebut, namun perubahan sub-sub seperti menghilangkan "Kedamaian" di ganti dengan "Kenyamanan" pada prinsipnya konsep yang di uraikan sama yaitu untuk melaksanakan dan meningkatkan budaya 7K dalam lingkungan sekolah.

Proses melaksanakan dan meningkatkan budaya $7 \mathrm{~K}$ penjelasan masing-masing sub dari 7K sebagai berikut: 


\section{Keamanan}

Menurut Suwanto dkk (2008) keamanan lingkungan adalah tanggungjawab bersama. Lingkungan aman membuat warga tenang. Dalam kaitanya hal ini menjaga keamanan sekolah bukan sepenuhnya oleh satpam sekolah, namun oleh siswa itu sendiri dan seluruh warga sekolah yang terlibat. Lingkungan sekolah yang aman akan membuat warga sekolah terbebas dari rasa takut, sehingga dalam proses belajar mengajar berjalan dengan lancar dan siswa akan mudah mengekspresikan dan mengembangkan potensi yang ada di individu masing-masing.

Nilai keamanan harus menjadi landasan bagi siswa dan warga sekolah dalam berbagai kegiatan baik di dalam maupun di luar sekolah. Beberapa kegiatan yang perlu diperhatikan, antara lain: (1) menjaga kemaanan diri, teman, warga sekolah, barang-barang perlengkapan sekolah, dan hak milik dalam belajar di ruang kelas, laboratorium, kegiatan olahraga, dan kegiatan belajar dan bermain lainnya. (2) Menjaga keamanan dan keutuhan hak milik pribadi dan sekolah dari pihak-pihak yang mengganggu baik dari dalam maupun luar sekolah. (3) Menjaga keamanan sekolah dar pengaruh negatif baik dari luar maupun dalam sekolah, seperti peredaran obat-obatan terlarang (narkoba), adu domba dengan warga sekolah lainnya, dan upaya provokasi lainnya (Departemen Pendidikan Nasional, 2001).

\section{Kenyamanan}

Menurut Rukky Santoso (2003) bahwa kenyamanan sebetulnya hanya sebuah persepsi, sebuah gambaran dipikiran yang diidentifikasi sebagai enak, nikmat, positif, dan sesuai. Ini adalah gambaran relatif. Untuk seseorang bisa jadi nikmat dan nyaman, tapi untuk orang lain mungkin saja membosankan. Paradigma nyaman itu sendiri tidak jelas benar. Perasaan nyaman adalah kebutuhan setiap orang, orang yang tidak nyaman dengan orang lain, biasanya akan menjauhi membuat orang lain merasa nyaman adalah hal pokok dalam sebuah pergaulan, sebab akan menjamin kelanggengannya. Toleransi juga merupakan salah satu bentuk kenyamanan antar sesama. Semakin kita membuat orang merasa nyaman, maka semakin banyak teman yang menghampiri. Efek dari membuat nyaman orang lain adalah kita tidak memiliki musuh atau saingan. Kemanapun dan dimanapun berada, jika mampu membuat orang nyaman, maka keberadaan kita akan mudah diterima orang lain (Hegar Pangarep, 2010).

Kebersihan

Menurut Departemen Pendidikan Nasioal, (2001) beberapa kegiatan yang perlu diperhatikan dalam membudayakan nilai-nilai kebersihan, anatara lain: (1) Membiasakan siswa dan warga sekolah membuang sampah pada tempatnya; (2) Mengingat dan menegur siswa atau warga sekolah yang membuang sampah di sembarang tempat; (3) Mengatur jadwal piket siswa untuk membersihkan ruang belajar, taman sekolah, dan lingkungan sekolah; (4) Membiasakan siswa menjaga kebersihan dan kesehatan badan, kerapihan pakaian (bersih dan sopan), rambut, kuku, dan semacamnya.

Termasuk menjaga kebersihan gigi, kulit, dan rambut, selain tertib menyisihkan pakaian bekas dari luar rumah (bepergian) tidak dibiasakan membawanya memasuki kamar tidur agar tidak mencemari ruangan tidur, diantara dalam menjaga kebersihan adalah menjaga kebersihan tangan, menjaga kebersihan kaki, cara makan sehat, dan ketertiban

Menurut Departemen Pendidikan Nasional (2001) Disiplin atau tertib adalah suatu sikap konsisten dalam melakukan sesuatu. Beberapa kegiatan yang perlu dibudayakan di sekolah berkaitan dengan nilai dasar antara lain: (1) Tepat waktu masuk sekolah, mengikuti pertemuan, atau kegiatan lain yang dijadwalkan sekolah; (2) Menumbuh kembangkan sifat sabar dan membiasakan budaya antri bagi siswa dan warga sekolah dalam mengikuti berbagai kegiatan sekolah dan luar sekolah yang berlangsung bersama-sama; (3) Menjaga suasana ketenangan belajar baik di kelas, perpustakaan, laboratorium, mauoun tempat lainnya; dan (4) Mentaati jadwal kegiatan sekolah, seperti penggunaan dan peminjaman buku di perpustakaan, penggunaan laboratorium dan suber belajar lainnya. 
Menurut Masan dan Rachmat (2006) Di dalam lingkungan sekolah ada tata tertib yang harus ditaati oleh seluruh warga sekolah. Tata tertib di sekolah bertujuan untuk menciptakan ketertiban, kelancaran, dan keamanan sekolah dalam proses kegiatan belajar mengajar. Jika semua warga sekolah menaati tata tertib, maka keamanan, kenyamanan, dan keberhasilan belajar dapat dicapai.

Keindahan

Untuk menjaga keindahan sekolah salah satunya dengan cara mengajarkan siswa tentang cara membersihkan lingkungan sekolah meliputi keindahan ruangan kelas, keindahan halaman sekolah, dan keindahan taman sekolah

Sekolah yang indah akan mendapatkan suasana yang asri dan enak dipandang sehingga tentu akan membuat proses belajar mengajar menjadi nyaman. Cara menjaga keindahan dengan menciptakan suasana yang bersih, menjaga kerindangan sekolah dan tata letak yang baik. Sekolah dan lingkungan mempunyai banyak ruangan yang digunakan untuk beraktifitas, seperti ruang kelas, ruang guru, ruang perpustakaan, kantin sekolah, ruang ganti, ruang UKS, lingkungan sekolah seperti halaman sekolah dan taman sekolah. Untuk itu sebagai warga sekolah harus dapat menjaga keindahan dengan baik agar dalam proses belajar mengajar dapat terlaksana dengan nyaman.

Kekeluargaan

Menurut Masan dan Rachmat (2006) Keluarga merupakan unit terkecil dalam masyarakat untuk menumbuhkan kesadaran menjaga keamanan dan ketertiban di lingkungan yang lebih besar. Hal itu dapat terwujud jika di dalam keluarga ada kepatuhan dan ketaatan terhadap aturan kelurga, tata krama, dan adat istiadat. Jadi, apabila setiap anggota keluarga telah memiliki kepatuhan dan ketaatan terhadap tata krama dan aturan keluarga, akan terciptalah kehidupan yang harmonis, rukun, dan damai. Hal-hal yang mendukung suasana harmonis dalam keluarga, antara lain: (1) Beribadah bersama; (2) Saling mencintai, menghargai, dan tolong menolong antar anggota keluarga; (3) Mengakui keberadaan dan fungsi atau kedudukan masing-masing anggota keluarga, dan (4) Menghargai pendapat satu sama lain

Menurut Departemen Pendidikan Nasional (2001) Tata hubungan yang paling penting untuk untuk diperhatikan sekolah dalam membuat tata krama dan tata tertib kehidupan sosial di sekolah adalah tata hubungan siswa.hal ini sangat penting karena siswa adalah subjek pendidikan dan pembelajaran yang sedang mengalami pertumbuhan kejiwaan, pembentukan kepribadian dan pengembangan potensi yang dimilikinya. Oleh karena itu, tata tertib dan peraturan perlu mengatur hubungan: (1) Siswa dengan siswa; (2) Siswa dengan guru dan kepala sekolah; (3) Siswa dengan tenaga administratif; (4) Siswa dengan masyarakat (tamu, orangtua, tokoh masyarakat, dsb); (5) Siswa dengan lingkungannya.

Sekolah berkewajiban untuk membuat tiap murid merasa bahwa mereka diperlakukan dengan cara kasih sayang dan adil, karena perlakuan yang mereka terima, menyebabkan mereka merasa bahwa cara itulah yang harus mereka ikuti dalam bergaul dengan orang lain. Di lingkungan formal seperti sekolah tentunya menjunjung tinggi sikap dan norma yang berlaku, Hubungan antar warga di sekolah harus berjalan dengan baik misalnya sikap siswa yang menghormati guru, interaksi antar warga di sekolah dengan baik akan menciptakan suasana yang nyaman.

\section{Kerindangan}

Penghijauan sekolah merupakan usaha untuk membuat susasana sekolah menjadi sejuk dan rindang. Sekolah yang sejuk dan rindang akan membuat kita betah belajar, sekaligus menciptakan lingkungan yang sehat. Cara menghijaukan lingkungan adalah dengan menanam pepohonan di taman atau kebun sekolah. Di taman atau kebun, kita bisa menanam pohon pelindung, pohon hias, dapur hidup, apotek hidup, dan bunga-bunga yang indah (Dwi Tyas Utami, dkk, 2006)

Taman sekolah menjadi bagian dari lingkungan sekolah. Keindahannya harus dijaga dan di pelihara dengan baik. Tanaman pada taman tersebut harus di rawat setiap hari. 
Semua warga sekolah harus saling membantu dalam merawat taman sekolah. Lingkungan sekolah menjadi asri karena adanya taman. Taman sekolah ditanami oleh berbagai macam tanaman hias. Tanaman akan tumbuh subur dan tidak diganggu oleh hama jika warga sekolah merawatnya dengan rajin.

\section{METODE}

Penelitian ini merupakan penelitian deskriptif, penelitian ini dimaksudkan untuk mengumpulkan informasi mengenai status suatu gejala yang ada, yaitu keadaan gejala menurut apa adanya pada saat penelitian dilakukan, adapun tujuannya untuk mengetahui penerapan budaya 7K bagi siswa kelas IV, V, VI di SD Negeri 7 Kebumen, Kecamatan Kebumen. Metode yang digunakan dalam penelitian ini adalah metode survei dan teknik pengumpulan data dengan menggunakan angket yang berupa sejumlah pertanyaan tertulis yang diberikan kepada responden untuk diisi sesuai keadaannya.

Variabel dalam penelitian ini ialah budaya 7k yang diterapkan di SD Negeri 7 Kebumen yaitu: keamanan, kenyamanan, kebersihan, ketertiban, kekeluargaan, keindahan, dan kerindangan. Definisi operasional dari masing-masing faktor antara lain keamanan yaitu siswa turut menjaga kemanan sekolah, kelas dan diri sendiri, kenyamanan yaitu siswa merasa nyaman dengan fasilitas, sarana, prasarana, serta hubungan yang baik antar warga sekolah, kebersihan yaitu siswa menjaga kebersihan diri dan sekolah, ketertiban yaitu siswa mematuhi peraturan sekolah dan tertib mengikuti kegiatan belajar megajar di sekolah, keindahan yaitu siswa menjaga keindahan kela dan halaman sekolah, kekeluargaan yaitu siswa menjaga hubungan dan interaksi yang baik antar warga sekolah, serta kerindangan yatiu siswa ikut serta menjaga dan memelihara tanaman dan taman di sekolah.

Untuk mengetahui penerapan siswa dalam melaksanakan budaya 7K di sekolah digunakan angket dengan butir-butir pertanyaan yang berkaitan dengan faktor-faktor yang terkandung di dalam 7K. Pertanyaan yang berhubungan dengan keamanan sebanyak 6 pertanyaan, yang berhubungan dengan kenyamanan sebanyak 5 pertanyaan, yang berhubungan dengan kebersihan sebanyak 6 pertanyaan, yang berhubungan dengan ketertiban sebanyak 6 pertanyaan, yang berhubungan dengan keindahan sebanyak 6 pertanyaan, yang berhubungan dengan kekeluargaan sebanyak 6 pertanyaan, dan yang berhubungan dengan kerindangan sebanyak 5 pertanyaan, sehingga total pertanyaan sejumlah 40 pertanyaan.

\section{HASIL DAN PEMBAHASAN}

Penelitian ini bertujuan untuk mengungkap penerapan budaya 7K yaitu (1) Keamanan, (2) Kenyamanan, (3) Kebersihan, (4) Ketertiban, (5) Keindahan, (6) Kekeluargaan, (7) Kerindangan) pada SD Negeri 7 Kebumen Kecamatan Kebumen. Sumber data dalam penelitian ini diperoleh dari siswa kelas IV, V, VI. Jumlah siswa kelas IV sebanyak 35 siswa, tidak berangkat 1 siswa dikarenakan sakit sehingga data yang di peroleh sebanyak 34 siswa, jumlah siswa kelas $\mathrm{V}$ sebanyak 35 siswa, tidak berangkat 2 siswa dikarenakan sakit sehingga data yang di peroleh sebanyak 33 siswa, jumlah siswa kelas VI sebanyak 34 siswa, tidak berangkat 1 siswa dikarenakan sakit sehingga data yang di peroleh sebanyak 33 siswa, dengan demikian jumlah keseluruhan siswa yang diteliti sebanyak 100 siswa.

Data penelitian ini diperoleh dengan menggunakan instrumen angket setelah melalui uji coba gugur 5 butir sehingga ada 35 pertanyaan dan memperoleh hasil keseluruhan seperti terlihat pada Tabel 1.

Tabel 1. Deskripsi hasil keseluruhan penerapan budaya 7K di SD Negeri 1 Bandung

\begin{tabular}{|c|c|c|}
\hline Katerogi & Faktor & Presentase \\
\hline \multirow{2}{*}{ Sangat Baik } & Ketertiban & \multirow{2}{*}{$28,6 \%$} \\
\cline { 2 - 2 } & Kekeluargaan & \\
\hline \multirow{3}{*}{ Baik } & Keamanan & \\
& Kenyamanan & \multirow{2}{*}{$57,1 \%$} \\
& Kebersihan & \\
& Keindahan & \\
\hline
\end{tabular}




\begin{tabular}{|c|c|c|} 
Cukup & Kerindangan & $14,3 \%$ \\
\hline Tidak Baik & - & $0 \%$ \\
\hline Jumlah & $100 \%$ \\
\hline
\end{tabular}

Dari Tabel 1 terlihat bahwa kategori sangat baik terdapat 2 faktor yaitu ketertiban dan kekeluargaan dengan presentase 28,6 \%, kategori baik terdapat 4 faktor yaitu keamanan, kenyamanan, kebersihan dan keindahan dengan presentase $57,1 \%$, kategori cukup terdapat 1 faktor yaitu kerindangan dengan presentase $14,3 \%$ dan kategori tidak baik dengan presentase $0 \%$.

Berdasarkan penelitian yang telah dilakukan dapat diketahui bahwa penerapan keamanan sekolah sudah dilaksanakan dengan baik. Hal ini dapat dilihat dari hasil penelitian bahwa dari 100 responden dapat terlihat bahwa sebagian besar siswa menjawab dengan kategori baik, artinya bahwa para siswa mengetahui hal-hal tentang menjaga keamanan diri sendiri dan sekolah yang merupakan tanggungjawab seluruh warga sekolah, kesadaran diri siswa untuk menjaga keamanan dirinya dengan cara menjaga perlengkapan dan barangbarang milik sendiri serta siswa tidak mudah percaya dengan orang yang tidak di kenal di lingkungan sekolah. Pelaksanaan budaya keamanan tersebut juga diterapkan melalui peraturan yang diterapkan sekolah seperti melarang siswa membawa barang mewah seperti handphone, perhiasan dan mainan mahal.

Dilihat dari faktor kenyamanan di tercipta karena telah tersedianya sarana, prasarana dan fasilitas yang menunjang proses belajar mengajar seperti ruang kelas yang terawat dengan kondisi bangunan yang kokoh, lapangan yang luas, kamar mandi yang bersih, peralatan dikelas maupun di luar kelas yang lengkap, serta hubungan yang baik antar warga di sekolah membuat warga sekolah merasa nyaman melakukan aktivitas belajar mengajar di sekolah.

\section{SIMPULAN}

Berdasarkan hasil penelitian yang untuk menjawab rumusan masalah "Bagaimana pelaksanaan penerapan budaya $7 \mathrm{~K}$ (keamanan, kenyamanan, kebersihan, ketertiban, keindahan, kekeluargaan, dan kerindangan) yang dilakukan oleh siswa kelas IV, V, VI di SD Negeri 7 Kebumen, Kecamatan Kebumen" mendapatkan fakta bahwa penerapan yang dilakukan oleh siswa kelas IV, V, VI dalam melaksanakan budaya 7K di sekolah adalah baik. $\mathrm{Hal}$ ini dapat dilihat dari 7 faktor yang diterapkan ada 4 faktor yang dikategorikan baik yaitu keamanan, kenyamanan, kebersihan, keindahan dengan presentase 57,1\%, 2 faktor dengan hasil penelitian sangat baik yaitu ketertiban dan kekeluargaan dengan presentase $28,6 \%$, 1 faktor dengan hasil cukup adalah kerindangan dengan presentase $14,3 \%$, dan kategori tidak baik dengan presentase $0 \%$

\section{DAFTAR PUSTAKA}

Departemen Pendidikan Nasional. (2001). Manajemen peningkatan mutu berbasis sekolah. jakarta

Departemen Pendidikan Nasional. (2008). Peraturan Menteri Pendidikan Nasional nomor 39 tahun 2008 tentang standar penilaian pendidikan. Novindo Pustaka Mandiri

Djohar. (1999). Reformasi dan masa depan pendidikan di Indonesia. Yogyakarta: Pustaka Pelajar

Fufindo, O. G. (2013). Pembinaan kesiswaan di sekolah menengah pertama negeri kecamatan sungayang kebupaten tanah datar. Jurnal Bahana Manajemen Pendidikan, 1(1).

Masan dan Rachmat. (2006). PKN pendidikan kewarganegaraan untuk SD/MI kelas 5. Jakarta: Grafindo

Pangarep, H. (2010). 101 tips kilat personality plus. Jakarta: PT. Buku Kita

Santoso, R. (2003). Right brain mengembangkan kemampuan otak kanan untuk kkehidupan yang lebih berkualitas. Jakarta: PT. Gramedia Pustaka Utama 
Suwanto, W., \& Setyawan, D. (2008). Ayo belajar ilmu pengetahuan sosial kelas 2. Yogyakarta: Kanisius

Syafaruddin. (2002). Manajemen mutu terpadu dalam pendidikan. Jakarta: Grasindo

Tilaar, H. A. R. (1999). Pendidikan kebudayaan dan masyarakat madani Indonesia: strategi reformasi pendidikan nasional. PT Remaja Rosdakarya.

Utami D,T., dkk. (2006). IImu pengetahuan sosial untuk sekolah dasar kelas III. Jakarta: Erlangga 